\title{
Atrial Natriuretic Peptides, Right Atrial Infarction and Prognosis of Patients with Myocardial Infarction-A Single-Center Study
}

\author{
Michal Kacprzak * $+^{+}$, Magdalena Brzeczek ${ }^{+}$(D) and Marzenna Zielinska \\ Department of Interventional Cardiology, Medical University of Lodz, 92-213 Lodz, Poland; \\ magdalena.brzeczek@gmail.com (M.B.); marzenna.zielinska@umed.lodz.pl (M.Z.) \\ * Correspondence: michal.kacprzak@umed.lodz.pl \\ + These authors contributed equally to this paper.
}

Citation: Kacprzak, M.; Brzeczek, M.; Zielinska, M. Atrial Natriuretic

Peptides, Right Atrial Infarction and Prognosis of Patients with Myocardial Infarction-A Single-Center Study. Biomolecules 2021, 11, 1833. https:// doi.org/10.3390/biom11121833

Academic Editor: Pietro Scicchitano

Received: 8 October 2021

Accepted: 1 December 2021

Published: 4 December 2021

Publisher's Note: MDPI stays neutral with regard to jurisdictional claims in published maps and institutional affiliations.

Copyright: (c) 2021 by the authors. Licensee MDPI, Basel, Switzerland. This article is an open access article distributed under the terms and conditions of the Creative Commons Attribution (CC BY) license (https:/ / creativecommons.org/licenses/by/ $4.0 /)$.
Abstract: Atrial natriuretic peptide (ANP) is secreted in response to the stretching of the atrial wall. Atrial ischemia most likely impairs the ability of atrial myocytes to produce ANP. Atrial infarction (AI) is rarely diagnosed but not infrequently associated with myocardial infarction (MI). The aim of the study was to assess the association between $\mathrm{AI}$ and the prognostic value of $\mathrm{N}$-terminal proANP (NT-proANP) in patients with MI treated with primary percutaneous coronary intervention (PCI). We evaluated data of 100 consecutive patients. Plasma levels of NT-proANP were measured by the ELISA method. ECG recordings were interpreted to diagnose AI according to Liu's criteria. All patients were followed-up prospectively for 12 months for the manifestation of major adverse cardiovascular events (MACE), defined as unplanned coronary revascularization, stroke, reinfarction or all-cause death. AI was diagnosed in 36 patients. $14 \%$ of patients developed MACE. AI did not affect the incidence of MACE or any of its components, nor the patients' prognosis. NT-proANP revealed to be a strong predictor of death but was not associated with other adverse events. Conclusions: AI in patients with MI treated with primary PCI is not connected with their prognosis nor affects the usefulness of NT-proANP in predicting death during the 12-month follow-up.

Keywords: myocardial infarction; atrial infarction; N-terminal proatrial natriuretic peptide

\section{Introduction}

There are two natriuretic peptides, structurally similar but genetically distinct, that are produced and secreted mainly by the chambers of the heart: atrial natriuretic peptide (ANP) secreted from the atria and B-type natriuretic peptide (BNP) secreted from the ventricles [1,2]. ANP, like all natriuretic peptides, is synthesized as a preprohormone. The first 25 amino acids comprise a signal sequence, and the next following 126 amino acid peptides constitute proANP, which is the major form of ANP stored in secretory atrial granules. When released from these granules, proANP is immediately split by corin and forms a biologically active 28 amino acid peptide-ANP and inactive N-terminal proANP (NT-proANP). After being secreted in response to the stretching of the atrial wall, ANP enters the coronary sinus and is transported via the circulatory system to all organs possessing suitable receptors (kidneys, lungs, adipose tissue, adrenal glands, brain, heart, testes and vascular smooth muscle tissue). The active ANP is decomposed by the action of neutral endopeptidase and by binding to the natriuretic peptide receptors. The approximate ANP plasma half-time is approximately 2-3 min. Released in equimolar amounts NTproANP, slowly eliminated by kidneys, appears to have more practical diagnostic use [3-5].

Atrial infarction (AI) is a rarely diagnosed disease. Usually, AI is a consequence of an atherosclerotic process, accompanying $0.7-42 \%$ of ventricular myocardial infarctions. AI more often appears in the right atrium, accounting for $81 \%$ to $98 \%$ of cases [6,7]. The occurrence of AI may be associated with a higher incidence of supraventricular arrhythmias (atrial fibrillation, wandering pacemaker, atrial tachycardia or atrial premature complexes) 
than in ventricular infarctions alone (61-74\% vs. $8 \%$ ), signs and symptoms of heart failure due to loss of 'atrial kick' or with thromboembolic events [8,9].

Although described for the first time almost 100 years ago, there are still no validated criteria for diagnosing AI, the most recognized electrocardiographic criteria are those developed by Liu et al. in 1961, taking into account the deviation of the P-Ta segment as major criteria, and changes in the morphology of the $\mathrm{P}$ wave as minor criteria (Table 1) [10].

Table 1. Electrocardiographic diagnostic criteria for atrial infarction based on Liu et al. [10].

\begin{tabular}{cc}
\hline \multirow{3}{*}{ Major } & $\begin{array}{r}\text { 1. P-Ta-segment elevation }>0.5 \mathrm{~mm} \text { in leads V5-V6 and reciprocal depression of P-Ta } \\
\text { segment in V1 and V2 leads }\end{array}$ \\
\cline { 2 - 3 } & $\begin{array}{r}\text { 2. P-Ta-segment elevation }>0.5 \mathrm{~mm} \text { in lead I and reciprocal depression of P-Ta segment } \\
\text { in II and III leads }\end{array}$ \\
\cline { 2 - 3 } Minor & $\begin{array}{c}\text { Abnormal P-waves, flattering of P-wave in M-shape or W-shape, irregular or notched } \\
\text { P-wave }\end{array}$ \\
\hline
\end{tabular}

There are several reports presenting a correlation of the concentration of ANP with atrial dysfunction due to various causes. In the case of chronic heart failure, plasma ANP levels increase with the severity of heart failure [11]. As ANP is known to be synthesized in an energy-dependent pathway in the atrial myocytes, the decreased intracellular energy supply caused by atrial ischemia most likely impairs the ability of atrial myocytes to produce ANP [12]. In patients with acute myocardial infarction, regardless of the infarct-related artery (IRA), a decrease in plasma ANP levels soon after the incident has been reported [13]. In the animal model of myocardial infarction, the secretion of ANP increases in the first half an hour and decreases substantially during the next hours of observation [14]. These results prove that the rapid release of ANP stored in the secretory granules in the atria, caused by stretching the walls of the atria, is followed by a period of time with an inadequate level of the peptide. Insufficient endogenous ANP during acute myocardial (both ventricular and atrial) infarction might promote left ventricular remodeling, hemodynamic deterioration and worsen patients' prognosis.

The aim of the study was to assess the association between AI and the prognostic value of NT-proANP in patients with ST-segment elevation myocardial infarction (STEMI) treated with primary percutaneous coronary intervention (PCI).

\section{Materials and Methods}

\subsection{Study Population}

In the prospective study, we enrolled 100 consecutive patients admitted to the Department of Interventional Cardiology with the diagnosis of STEMI between the years 2017-2019. As the artery providing blood supply to the right atrium typically originates from the 1st segment of the right coronary artery (RCA), to assure the affected atrium will be the right one, we restricted the included patients to those with RCA diagnosed as IRA. Patients with an estimated survival time of less than 6 months, persistent atrial fibrillation, Wolff-Parkinson-White syndrome, Lown-Ganong-Levine syndrome, with an implanted electrotherapy device, mitral stenosis, significant mitral regurgitation, significant tricuspid regurgitation or without successful primary PCI meant as lack of TIMI III flow were excluded from the study. Local ethics committee approved the course of the study, and informed consent was given by all its participants.

\subsection{Study Protocol}

Coronary angiography with subsequent primary PCI was performed within $60 \mathrm{~min}$ from admission in all patients. All eligible patients received standard drug therapy (aspirin, ticagrelor or clopidogrel, beta-blockers, ACE-inhibitors and statins). All included patients 
had a successful primary PCI on IRA with drug-eluting stent implantation or balloon angioplasty. Repeated ECG recordings were interpreted in order to reveal the occurrence of Liu's criteria of AI. Echocardiography was performed in all patients prior to discharge from hospital. We assessed left ventricular function using the ejection fraction (LVEF) by the modified Simpson method. The following data were also collected for evaluation: age, sex, heart rate, systolic blood pressure, signs of heart failure on admission to hospital (according to the Killip classification) and coronary artery disease (CAD) risk factors (hypertension, diabetes, hyperlipidemia, family history of CAD and cigarette smoking).

All patients were followed up prospectively for 12 months for the occurrence of major adverse cardiovascular events (MACE), determined as necessity to perform unplanned coronary revascularization procedure (PCI or $\mathrm{CABG})$, stroke, reinfarction or death from any cause.

\subsection{NT-proANP Assay}

For determination of NT-proANP plasma concentration, blood was drawn into tubes with EDTA on admission to hospital and on the 4th day of hospitalization. Within $30 \mathrm{~min}$ from collection, plasma samples were centrifuged, frozen and stored until assay at temperature $-62{ }^{\circ} \mathrm{C}$. A NT-proANP assay was performed by sandwich ELISA (enzyme-linked immunosorbent assay) test, using a commercial kit BioVendor Human NT-proANP ELISA (BioVendor, Brno, Czech Republic). Complete blood count, renal and liver function tests, as well as NT-proBNP, were also determined.

\subsection{Statistical Analysis}

We presented categorical variables as frequencies with percentages, while continuous variables as means $\pm \mathrm{SD}$ or medians with interquartile range. The Shapiro-Wilk test was used to assess the normal distribution of variables. Non-parametric statistics were used for variables with other than normal distribution. Correlations were assessed using the Pearson correlation coefficient or Spearman's rank correlation coefficient. Student's $t$-test, Mann-Whitney U test and Kruskal-Wallis analysis of variance were used to compare continuous variables, whereas chi-squared test with Yates's correction for continuity was used to assess differences between categorical variables. To determine the association between independent variables and a dichotomous dependent variable (occurrence of MACE), stepwise logistic regression was used. To determine the suitability of NT-proANP levels in adverse cardiac events prediction, we used ROC curves. We performed all statistical analyses using STATISTICA 13.0 (StatSoft Inc., 2017; Tulsa, OK, USA). A $p$-value $<0.05$ was considered statistically significant.

\section{Results}

Our cohort consisted of 39 women and 61 men aged $65(60 ; 72)$ years. 79\% of patients were in Killip class I. Coronary angiography revealed single-vessel disease in $33 \%$ of the group. Drug-eluting stents were implanted in $99 \%$ of patients. Other clinical features of the group and concomitant therapy are presented in Table 2.

Table 2. Patient characteristics, laboratory test, echocardiography findings and concomitant treatment in the whole study group and by subgroups depending on the diagnosis of right atrial infarction.

\begin{tabular}{ccccc}
\hline Patient Characteristic & $\mathbf{N}=\mathbf{1 0 0}$ & $\begin{array}{c}\text { Right Atrial Infarction } \\
\mathbf{( N = 3 6 )}\end{array}$ & $\begin{array}{c}\text { No Right Atrial Infarction } \\
\mathbf{( N = 6 4 )}\end{array}$ & $\boldsymbol{p}$ \\
\hline Age [years] & $65 \pm 10$ & $64 \pm 11$ & $66 \pm 10$ & 0.277 \\
\hline Women & $39(39 \%)$ & $10(28 \%)$ & $29(45 \%)$ & 0.084 \\
\hline Heart rate [beats/min] & $70(62 ; 80)$ & $70(64 ; 80)$ & $70(59 ; 80)$ & 0.437 \\
\hline Systolic blood pressure $[\mathrm{mmHg}]$ & $140 \pm 24$ & $140 \pm 29$ & $141 \pm 22$ \\
\hline
\end{tabular}


Table 2. Cont.

\begin{tabular}{|c|c|c|c|c|}
\hline Patient Characteristic & $\mathrm{N}=100$ & $\begin{array}{l}\text { Right Atrial Infarction } \\
\qquad(\mathrm{N}=36)\end{array}$ & $\begin{array}{l}\text { No Right Atrial Infarction } \\
\qquad(\mathrm{N}=64)\end{array}$ & $p$ \\
\hline Killip class II-IV & $21(21 \%)$ & $4(11 \%)$ & $17(27 \%)$ & 0.069 \\
\hline Hypertension & $64(64 \%)$ & $20(56 \%)$ & $44(69 \%)$ & 0.187 \\
\hline Diabetes & $28(28 \%)$ & $10(28 \%)$ & $18(28 \%)$ & 0.970 \\
\hline Hyperlipidemia & $22(22 \%)$ & $5(14 \%)$ & $17(27 \%)$ & 0.142 \\
\hline Family history of CAD & $21(21 \%)$ & $8(22 \%)$ & $13(20 \%)$ & 0.822 \\
\hline Current or former smoker & $61(61 \%)$ & $24(67 \%)$ & $37(58 \%)$ & 0.384 \\
\hline Troponin T max [ng/L] & $1990(738 ; 4198)$ & $2054(622 ; 3813)$ & $1968(770 ; 4436)$ & 0.906 \\
\hline Serum creatinine $[\mu \mathrm{mol} / \mathrm{L}]$ & $87(70 ; 107)$ & $92(79 ; 107)$ & $85(69 ; 104)$ & 0.239 \\
\hline NT-proANP-0 [ng/L] & $4038 \pm 1582$ & $4204 \pm 1630$ & $3945 \pm 1559$ & 0.435 \\
\hline NT-proANP-4 [ng/L] & $2561 \pm 1074$ & $2466 \pm 920$ & $2616 \pm 1156$ & 0.505 \\
\hline NT-proBNP [ng/L] & $924(422 ; 1782)$ & $985(260 ; 1816)$ & $923(467 ; 1705)$ & 0.511 \\
\hline $\begin{array}{c}\text { Atrial fibrillation during } \\
\text { hospitalization }\end{array}$ & $16(16 \%)$ & $4(11 \%)$ & $12(19 \%)$ & 0.317 \\
\hline Multi-vessel disease & $67(67 \%)$ & $30(83 \%)$ & $37(58 \%)$ & 0.009 \\
\hline $\mathrm{EF}[\%]$ & $51(47 ; 56)$ & $50(47 ; 55)$ & $53(46 ; 57)$ & 0.469 \\
\hline $\mathrm{LAVi}\left[\mathrm{mL} / \mathrm{m}^{2}\right]$ & $37(31 ; 44)$ & $38(31 ; 44)$ & $37(30 ; 44)$ & 0.968 \\
\hline $\mathrm{RAVi}\left[\mathrm{mL} / \mathrm{m}^{2}\right]$ & $25(19 ; 31)$ & $27(20 ; 31)$ & $23(19 ; 30)$ & 0.436 \\
\hline \multicolumn{5}{|l|}{ Concomitant therapy: } \\
\hline Aspirin & $99(99 \%)$ & $36(100 \%)$ & $63(98 \%)$ & 0.769 \\
\hline P2Y12 receptor inhibitors & $100(100 \%)$ & $36(100 \%)$ & $64(100 \%)$ & \\
\hline GP IIb/IIIa blocker & $58(58 \%)$ & $22(61 \%)$ & $36(56 \%)$ & 0.636 \\
\hline Statins & $98(98 \%)$ & $35(97 \%)$ & $63(98 \%)$ & 0.743 \\
\hline Beta-blockers & $91(91 \%)$ & $33(92 \%)$ & $58(91 \%)$ & 0.850 \\
\hline ACE-inhibitors & $94(94 \%)$ & $35(97 \%)$ & $59(92 \%)$ & 0.563 \\
\hline
\end{tabular}

$\mathrm{ACE}$ = angiotensin-converting enzyme; $\mathrm{CAD}=$ coronary artery disease; $\mathrm{EF}=$ ejection fraction. GP = glycoprotein; LAVi = left atrial volume index; NT-proANP-0 = N-terminal pro-atrial natriuretic peptide on admission to hospital; NT-proANP-4 = N-terminal pro-atrial natriuretic peptide on the 4th day of hospitalization; NT-proBNP $=\mathrm{N}$-terminal pro-B-type natriuretic peptide; $\mathrm{RAVi}=$ right atrial volume index. Statistically significant differences $(p<0.05)$ are shown in bold.

\subsection{NT-proANP Levels-Relation to Clinical Data}

NT-proANP plasma concentration assessed on admission (NT-proANP-0) was 4039 $(2832 ; 5248) \mathrm{ng} / \mathrm{L}$, while on the 4th day of hospitalization (NT-proANP-4) $2562(1958 ; 3199)$ $\mathrm{ng} / \mathrm{L}$. In our group of patients, NT-proANP levels on admission were significantly higher than the values obtained on the 4 th day of hospitalization $(p<0.0001)$ (Figure 1$)$.

The occurrence of most CAD risk factors (hypertension, diabetes, smoking status, obesity, family history of cardiovascular diseases), history of previous MI, sex, heart rate, systolic blood pressure and administered therapy did not affect NT-proANP levels (Table 3). 


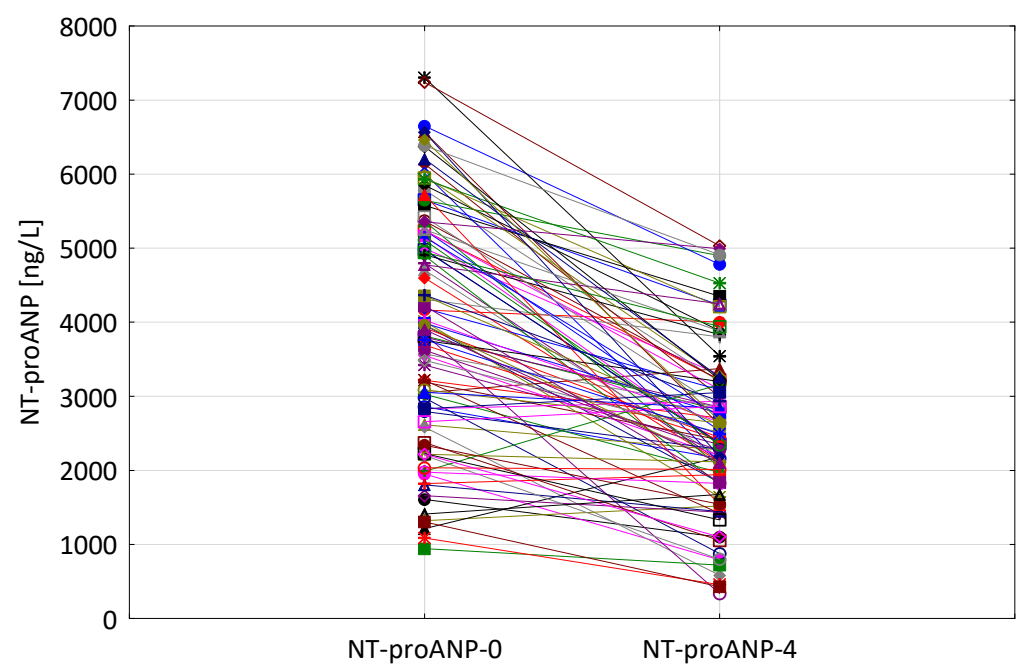

Figure 1. The comparison of NT-proANP concentrations on admission (NT-proANP-0) and on the 4th day of hospitalization (NT-proANP-4) in individual patients.

Table 3. Association between patient characteristics and NT-proANP concentrations on admission (NT-proANP-0) and on the 4 th day of hospitalization (NT-proANP-4).

\begin{tabular}{|c|c|c|c|c|c|}
\hline \multirow{3}{*}{ Sex } & \multirow{3}{*}{$\begin{array}{c}\text { men } \\
\text { women }\end{array}$} & \multicolumn{2}{|c|}{ NT-proANP-0 [ng/L] } & \multicolumn{2}{|c|}{ NT-proANP-4 [ng/L] } \\
\hline & & $3816(2584 ; 5245)$ & 402064 & $2453 \pm 1127$ & 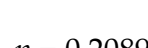 \\
\hline & & $4165(3484 ; 5249)$ & & $2731 \pm 976$ & \\
\hline \multirow{3}{*}{ Nutritional status } & normal & $4597(3571 ; 5357)$ & \multirow{3}{*}{$p=0.0915$} & $2641(2112 ; 3881)$ & \multirow{3}{*}{$p=0.1817$} \\
\hline & over-weight & $3694(2202 ; 4976)$ & & $2413(1824 ; 3163)$ & \\
\hline & obesity & $4492(2831 ; 5362)$ & & $2400(1537 ; 2996)$ & \\
\hline \multirow{2}{*}{ Hypertension } & yes & $4000(2705 ; 5203)$ & \multirow{2}{*}{$p=0.7988$} & $2485 \pm 1130$ & \multirow{2}{*}{$p=0.3428$} \\
\hline & no & $3755(2953 ; 5308)$ & & $2699 \pm 968$ & \\
\hline \multirow{2}{*}{ Diabetes } & yes & $3765 \pm 1462$ & \multirow{2}{*}{$p=0.2833$} & $2416 \pm 1039$ & \multirow{2}{*}{$p=0.4010$} \\
\hline & no & $4145 \pm 1623$ & & $2618 \pm 1090$ & \\
\hline \multirow{2}{*}{ Hyperlipidemia } & yes & $3467 \pm 1580$ & \multirow{2}{*}{$p=0.0546$} & $1961 \pm 1095$ & \multirow{2}{*}{$p=0.0026$} \\
\hline & no & $4200 \pm 1555$ & & $2731 \pm 1012$ & \\
\hline \multirow{2}{*}{ Family history of CAD } & yes & $3871 \pm 1542$ & \multirow{2}{*}{$p=0.5875$} & $2292 \pm 1041$ & \multirow{2}{*}{$p=0.1983$} \\
\hline & no & $4083 \pm 1599$ & & $2633 \pm 1078$ & \\
\hline \multirow{2}{*}{ Current or former smoker } & yes & $3793 \pm 1565$ & \multirow{2}{*}{$p=0.0515$} & $2465 \pm 1079$ & \multirow{2}{*}{$p=0.2644$} \\
\hline & no & $4423 \pm 1551$ & & $2713 \pm 1064$ & \\
\hline \multirow{2}{*}{ Killip class } & $\mathrm{I}$ & $3754(2375 ; 5235)$ & \multirow{2}{*}{$p=0.0071$} & $2389 \pm 993$ & \multirow{2}{*}{$p=0.0014$} \\
\hline & II-IV & $4976(3989 ; 5646)$ & & $3214 \pm 1143$ & \\
\hline \multirow{2}{*}{ Multi-vessel disease } & yes & $4073 \pm 1562$ & \multirow{2}{*}{$p=0.7590$} & $2629 \pm 1050$ & \multirow{2}{*}{$p=0.3781$} \\
\hline & no & $3969 \pm 1644$ & & $2426 \pm 1128$ & \\
\hline
\end{tabular}

Statistically significant differences $(p<0.05)$ are shown in bold.

We found moderate, significant correlations between age and NT-proANP levels $(\mathrm{r}=0.3770 ; p=0.0001$ and $\mathrm{r}=0.48128 ; p<0.0001$, respectively). Patients with diagnosed hypercholesterolemia had lower NT-proANP on the 4th day of hospitalization $(p=0.0026)$, whereas patients in Killip class II-IV on admission had higher NT-proANP concentrations at both time points ( $p=0.0071$ and $p=0.0014$, respectively). We found no relationship between NT-proANP levels and the extent of atherosclerotic lesions (single- vs. multi-vessel 
disease). There was a weak, but significant correlation between LVEF and NT-proANP-4 $(\mathrm{R}=-0.26 ; p=0.0100)$.

There were weak to moderate significant correlations between NT-proANP and creatinine $(\mathrm{R}=0.279 p=0.0049 ; \mathrm{R}=0.2003 p=0.0456$, respectively), NT-proBNP $(\mathrm{R}=0.2136$ $p=0.0329 ; \mathrm{R}=0.5473 p<0.0001$, respectively $)$ and C-reactive protein $(\mathrm{R}=0.2331 p=0.0196$; $\mathrm{R}=0.2180 p=0.0293$, respectively), hemoglobin $(\mathrm{R}=-0.3337 p=0.0007 ; \mathrm{R}=-0.3319$ $p=0.0007$, respectively) and lymphocyte count $(\mathrm{R}=-0.2960 p=0.0028 ; \mathrm{R}=-0.3880$ $p=0.0001$, respectively) (Table 4 ).

Table 4. Association between patient characteristics, laboratory tests, echocardiography findings and NT-proANP concentrations on admission (NT-proANP-0) and on the 4th day of hospitalization (NT-proANP-4).

\begin{tabular}{ccccc}
\hline & \multicolumn{2}{c}{ NT-proANP-0 [ng/L] } & \multicolumn{2}{c}{ NT-proANP-4 [ng/L] } \\
\cline { 2 - 5 } & r or $\mathbf{R}$ & $\boldsymbol{p}$ & $\mathbf{r}$ or $\mathbf{R}$ & $\boldsymbol{p}$ \\
\hline Age & $\mathbf{r}=\mathbf{0 . 3 7 7 0}$ & $\mathbf{0 . 0 0 0 1}$ & $\mathbf{r}=\mathbf{0 . 4 8 1 3}$ & $<\mathbf{0 . 0 0 0 1}$ \\
\hline Heart rate [beats/min] & $\mathrm{R}=-0.029$ & 0.7743 & $\mathrm{R}=-0.0522$ & 0.6060 \\
\hline Systolic blood pressure $[\mathrm{mmHg}]$ & $\mathrm{r}=-0.0696$ & 0.4911 & $\mathrm{r}=-0.1283$ & 0.2034 \\
\hline Serum creatinine $[\mu \mathrm{mol} / \mathrm{L}]$ & $\mathbf{R}=\mathbf{0 . 2 7 9}$ & $\mathbf{0 . 0 0 4 9}$ & $\mathbf{R}=\mathbf{0 . 2 0 0 3}$ & $\mathbf{0 . 0 4 5 6}$ \\
\hline NT-proBNP $[\mathrm{ng} / \mathrm{L}]$ & $\mathbf{R}=\mathbf{0 . 2 1 3 6}$ & $\mathbf{0 . 0 3 2 9}$ & $\mathbf{R}=\mathbf{0 . 5 4 7 3}$ & $<\mathbf{0 . 0 0 0 1}$ \\
\hline C-reactive protein $[\mathrm{mg} / \mathrm{L}]$ & $\mathbf{R}=\mathbf{0 . 2 3 3 1}$ & $\mathbf{0 . 0 1 9 6}$ & $\mathbf{R}=\mathbf{0 . 2 1 8 0}$ & $\mathbf{0 . 0 2 9 3}$ \\
\hline Hemoglobin $[\mathrm{g} / \mathrm{dL}]$ & $\mathbf{R}=-\mathbf{0 . 3 3 3 7}$ & $\mathbf{0 . 0 0 0 7}$ & $\mathbf{R}=-\mathbf{0 . 3 3 1 9}$ & $\mathbf{0 . 0 0 0 7}$ \\
\hline Lymphocyte count $\left[10^{3} / \mu \mathrm{L}\right]$ & $\mathbf{R}=-\mathbf{0 . 2 9 6 0}$ & $\mathbf{0 . 0 0 2 8}$ & $\mathbf{R}=-\mathbf{0 . 3 8 8 0}$ & $\mathbf{0 . 0 0 0 1}$ \\
\hline Troponin T max $[\mathrm{ng} / \mathrm{L}]$ & $\mathrm{R}=0.1346$ & 0.1819 & $\mathbf{R}=\mathbf{0 . 2 7 3 7}$ & $\mathbf{0 . 0 0 5 8}$ \\
\hline LVEF $[\%]$ & $\mathrm{R}=-0.1003$ & 0.3208 & $\mathbf{R}=-\mathbf{0 . 2 5 6 4}$ & $\mathbf{0 . 0 1 0 0}$ \\
\hline
\end{tabular}

Statistically significant correlations $(p<0.05)$ are shown in bold.

\subsection{Right Atrial Infarction-Relation to Clinical Data}

Liu's electrocardiographic criteria allowed us to diagnose right atrial infarction (RAI) in 36 patients (36\%), including 26 men and 10 women. The relationship between the electrocardiographic features of RAI and the presence of risk factors for CAD (family history of cardiovascular diseases, diabetes, arterial hypertension, smoking status and dyslipidemia) has not been established. RAI was also not related to the nutritional status of the patients and their sex. There were no significant relations between the diagnosis of RAI and the segment of the RCA subjected to primary PCI, but the multi-vessel disease was diagnosed significantly more often in this group $(p=0.0092)$. RAI was also not associated with LVEF and the indexed volumes of both left and right atrium.

We found that RAI diagnosis was not associated with NT-proANP concentrations, both on admission to hospital and on the 4th day of hospitalization $(p=0.4350 ; p=0.5046$, respectively, Figure 2a,b). According to pathophysiological expectations, patients with RAI tended to have a greater decrease in NT-proANP concentrations during the first days of hospitalization, but the difference did not reach predetermined statistical significance $(p=0.0718$, Figure 2c). 


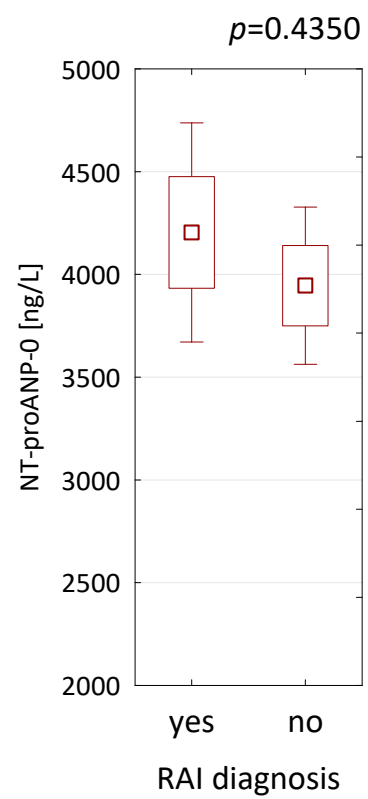

(a)

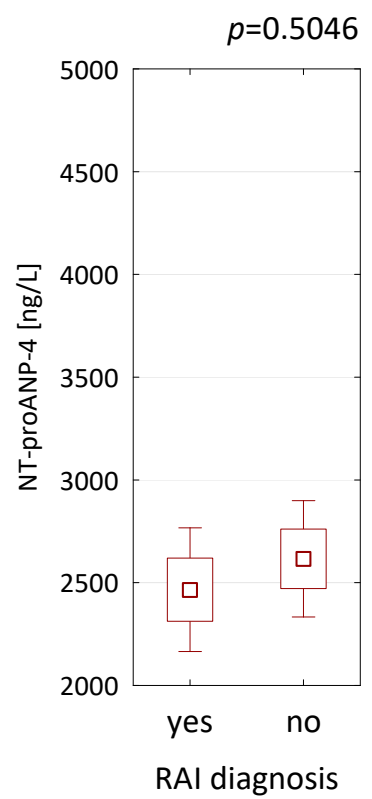

(b)

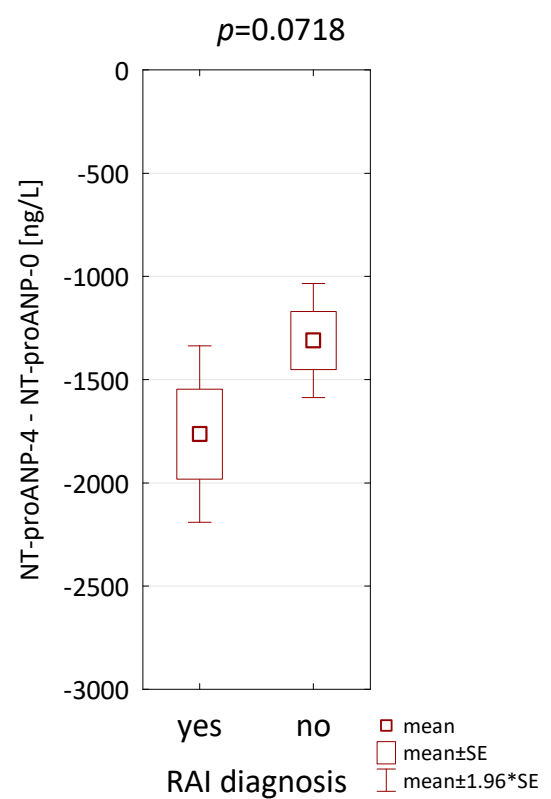

(c)

Figure 2. The comparison of NT-proANP concentrations on admission (NT-proANP-0) (a), on the 4th day of hospitalization (NT-proANP-4) (b) and the difference between two assays (c) depending on the diagnosis of right atrial infarction (RAI).

\subsection{NT-proANP Levels, Right Atrium Infarction-Prognostic Implications}

None of the patients died during the index hospitalization. After one year of followup, $14(14 \%)$ individuals developed MACE. Six $(6 \%)$ patients died, there were $5(5 \%)$ cases of reinfarction, $6(6 \%)$ patients underwent unscheduled revascularization procedures.

RAI did not affect the incidence of MACE $(p=0.9081)$ or any of its components $(p=0.7655$ for unscheduled revascularization, $p=0.7743$ for reinfarction and $p=0.7655$ for all-cause death).

The patients who died during follow-up had higher concentrations of NT-proANP both on admission $(p=0.0440)$ and on the 4 th day of STEMI $(p=0.0298)$. Analysis of the ROC curve revealed that both levels of NT-proANP were strong predictors of death after discharge from hospital $(\mathrm{AUC}=0.745 p=0.0104$ and $\mathrm{AUC}=0.743 p=0.0219$, respectively, Figure 3).

Patients with reinfarction during follow-up were no different from the others in terms of both NT-proANP levels ( $p=0.1452 ; p=0.5198$ ). Analysis of the ROC curves showed that this factor did not differentiate patients at risk of another myocardial infarction (AUC $=0.697 p=0.0567$ and $\mathrm{AUC}=0.632 p=0.1825$, respectively).

Likewise, patients demanding unscheduled revascularization did not differ from the others in terms of NT-proANP concentration $(p=0.8262 ; p=0.5082)$, which did not allow for the distinction of patients at risk (AUC $=0.537 p=0.8053$ and $\mathrm{AUC}=0.450 p=0.6407$ ).

There were no significant differences in the concentration of NT-proANP on admission to the hospital $(p=0.12)$ and on the 4 th day of hospitalization $(p=0.6538)$ between patients who developed MACE compared to uneventful survivors. Analysis of the ROC curves showed that this natriuretic peptide did not differentiate patients at risk of all adverse cardiovascular events taken together $(\mathrm{AUC}=0.630 p=0.1264$ and $\mathrm{AUC}=0.555 p=0.5315$, respectively, Figure 4). 


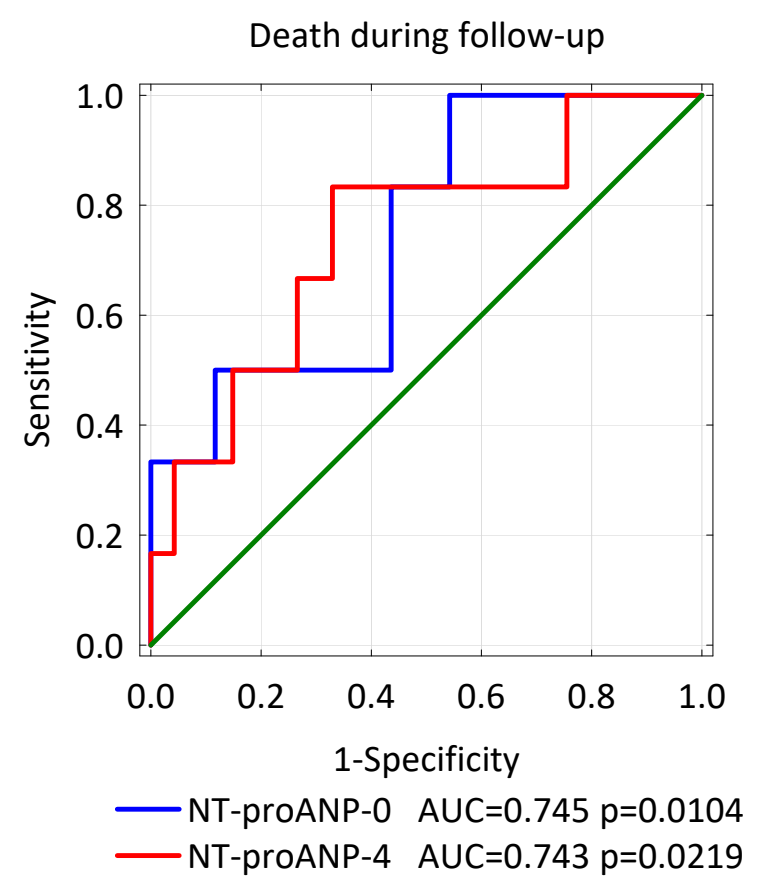

Figure 3. ROC curves-variables tested: the concentration of NT-proANP on admission to the hospital (NT-proANP-0) and on the 4th day of hospitalization (NT-proANP-4) in identifying patients at risk of death during follow-up.

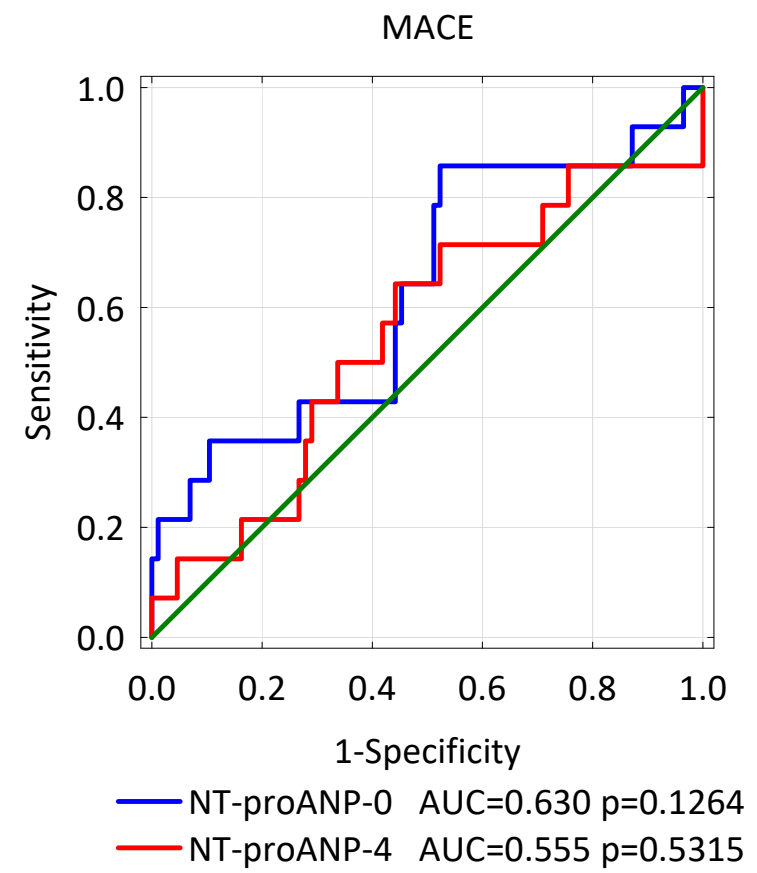

Figure 4. ROC curves-variables tested: the concentration of NT-proANP on admission to the hospital (NT-proANP-0) and on the 4th day of hospitalization (NT-proANP-4) in identifying patients at risk of MACE in the follow-up.

In multiple logistic regression analysis, among many considered parameters (age, diagnosis of RAI or diabetes, the maximum concentration of troponin $\mathrm{T}$, concentrations of creatinine, NT-proBNP and NT-proANP in both assays and LVEF), none of the factors revealed to be a significant predictor of MACE occurrence. 


\section{Discussion}

In our prospective study among patients with STEMI treated with primary PCI of RCA as IRA, we diagnosed RAI in $36 \%$ of patients. Although the diagnosis of RAI was associated with multi-vessel coronary artery disease, it had no relation to major coronary risk factors and did not affect prognosis in the one-year follow-up. We also did not notice any significant association with NT-proANP concentration assessed on admission to the hospital and on the 4th day of hospitalization.

In 1994, Yasuda et al. reported a case of a patient with right ventricular infarction with concomitant RAI, which was proven at autopsy. During hospitalization, ANP levels increased gradually but remained within the normal range despite abnormally high right atrial pressure. The authors concluded that atrial infarction probably impairs the ability of atrial myocytes to synthesize ANP, and its insufficient secretion may result in hemodynamic deterioration [12]. To our best knowledge, our study is the first to try to connect the incidence of atrial infarction with ANP secretion in a larger group of patients.

Lu et al. investigated the data of 224 patients to determine the effect of ECG abnormalities suggestive of atrial infarction on mortality after STEMI. They found abnormal $\mathrm{P}$ wave morphology (minor Liu criterion) in 35\% of the sample population and PR segment displacement in $31 \%$. None of the patients fulfilled any of the major criteria proposed by Liu et al. After adjusting for age, LVEF, peak troponin I and left main disease, PR displacement in any lead was associated with increased 1-year mortality (adjusted OR 6.22 (2.33-18.64)). Observed differences compared to our study may be related to different criteria of atrial ECG abnormalities applied, low participation of Caucasian race patients (22\% vs. $99 \%$ in our study) or conservative treatment of STEMI in every fourth patient [15].

A different approach was undertaken recently by Yildiz et al., who found atrial infarction in $8.7 \%$ of patients with inferior STEMI. The diagnosis was made by atrial branch involvement in coronary angiography, in which RCA was the IRA in $85 \%$ of cases. Surprisingly, none of the patients met the major Liu's criteria. The authors noted that the P-wave duration $>95 \mathrm{~ms}$ present in $87 \%$ of patients had higher sensitivity and specificity than any other ECG parameters in diagnosing atrial infarction [16].

Laukkanen et al., in a prospective study of 905 middle-aged men without heart failure, proved that NT-proANP could be considered as at least as strong a risk predictor as NT-proBNP in predicting death and the incidence of atrial fibrillation or heart failure [17].

Before the era of widespread invasive treatment of myocardial infarction, Omland et al., in a group of 139 patients treated conservatively (thrombolytic therapy only in $46 \%$ of patients), proved that NT-proANP was a significant and better prognostic factor than ANP in predicting death during one year of follow-up after myocardial infarction [18].

Hall et al. proved that 76 patients who died one year after myocardial infarction treated with thrombolysis had higher plasma levels of NT-proANP than those who survived. The increased risk of death associated with higher NT-proANP levels was independent of a history of prior MI, hypertension, diabetes, serum creatinine or atrial fibrillation. Serial measurements of NT-proANP during the first hours after enrollment showed a gradual decrease in its concentration [19].

Similar results were presented by Otterstad et al., who evaluated the impact of NT-proANP and echocardiographic parameters on prognosis after myocardial infarction treated conservatively. A total of 834 patients, of whom $64 \%$ received thrombolysis, with LVEF $\geq 40 \%$ were followed up for 24 months. A combined primary end-point defined as cardiac death, recurrent non-fatal myocardial infarction and heart failure requiring hospitalization or treatment with an angiotensin-converting enzyme inhibitor and diuretic therapy was observed in 102 patients. Baseline NT-proANP, but not echocardiographic left ventricular volumes predicted adverse cardiac events [20]. Unfortunately, there are no studies on the prognostic role of NT-proANP in patients after myocardial infarction treated invasively. In our group of well-treated patients, NT-proANP assessed both on admission and on the 4th day of STEMI proved to be a strong predictor of death in one-year follow-up, but it was not associated with other adverse events. 


\section{Limitations of the Study}

The most important limitation of the study is the small group of patients; therefore, our results should be interpreted with caution. The diagnosis of atrial infarction was based on the criteria by Liu et al., which have not been validated. The lack of generally accepted and validated criteria for the diagnosis of atrial infarction made the comparison of the obtained results much more difficult. To assure the affected atrium will be the right one, we restricted the included patients to those with RCA diagnosed as IRA. In addition, patients with persistent atrial fibrillation who have a worse prognosis were excluded.

\section{Conclusions}

Right atrial infarction in patients with STEMI treated with primary PCI of RCA as IRA is not connected with their long-term prognosis, nor affects the prognostic usefulness of NT-proANP in this group of patients.

Author Contributions: Conceptualization, M.B., M.K. and M.Z.; methodology, M.K. and M.Z.; formal analysis, M.K. and M.Z.; investigation, M.B. and M.K.; data curation, M.B.; writing-original draft preparation, M.K. and M.B.; writing-review and editing, M.K., M.B. and M.Z.; visualization, M.K.; supervision, M.Z.; project administration, M.B. and M.Z.; funding acquisition, M.B. and M.Z. All authors have read and agreed to the published version of the manuscript.

Funding: The study was supported by a grant from the Medical University of Lodz for young scientists and doctoral candidates (No: MB 502-14-320).

Institutional Review Board Statement: The study was conducted according to the guidelines of the Declaration of Helsinki and approved by the Bioethics Committee of the Medical University of Lodz (No: RNN/242/16/KE; date of approval: 11 October 2016).

Informed Consent Statement: Informed consent was obtained from all subjects involved in the study.

Data Availability Statement: The data presented in this study are available on request from the corresponding author.

Conflicts of Interest: The authors declare no conflict of interest. The funders had no role in the design of the study; in the collection, analyses, or interpretation of data; in the writing of the manuscript, or in the decision to publish the results.

\section{References}

1. Potter, L.R.; Yoder, A.R.; Flora, D.R.; Antos, L.K.; Dickey, D.M. Natriuretic Peptides: Their Structures, Receptors, Physiologic Functions and Therapeutic Applications. Handb. Exp. Pharmacol. 2009, 191, 341-366. [CrossRef]

2. Saito, Y. Roles of Atrial Natriuretic Peptide and Its Therapeutic Use. J. Cardiol. 2010, 56, 262-270. [CrossRef] [PubMed]

3. Nakao, K.; Sugawara, A.; Morii, N.; Sakamoto, M.; Yamada, T.; Itoh, H.; Shiono, S.; Saito, Y.; Nishimura, K.; Ban, T. The Pharmacokinetics of Alpha-Human Atrial Natriuretic Polypeptide in Healthy Subjects. Eur. J. Clin. Pharmacol. 1986, 31, 101-103. [CrossRef] [PubMed]

4. Yandle, T.G.; Richards, A.M.; Nicholls, M.G.; Cuneo, R.; Espiner, E.A.; Livesey, J.H. Metabolic Clearance Rate and Plasma Half Life of Alpha-Human Atrial Natriuretic Peptide in Man. Life Sci. 1986, 38, 1827-1833. [CrossRef]

5. Svanegaard, J.; Johansen, J.B.; Klitgaard, N.A.; Thayssen, P.; Haghfelt, T. Correlation Between Serial Changes in Left-Sided Heart Chambers and Atrial Natriuretic Peptide and N-Terminal Pro Atrial Natriuretic Peptide after a First Myocardial Infarction: An Echocardiographic Study. Scand. Cardiovasc. J. 1999, 33, 355-361. [CrossRef] [PubMed]

6. Lu, M.L.R.; Venecia, T.D.; Patnaik, S.; Figueredo, V.M. Atrial Myocardial Infarction: A Tale of the Forgotten Chamber. Int. J. Cardiol. 2016, 202, 904-909. [CrossRef] [PubMed]

7. Gardin, J.M.; Singer, D.H. Atrial Infarction: Importance, Diagnosis, and Localization. Arch. Intern. Med. 1981, 141, 1345-1348. [CrossRef] [PubMed]

8. Cushing, E.H.; Feil, H.S.; Stanton, E.J.; Wartman, W.B. Infarction of the Cardiac Auricles (Atria): Clinical, Pathological, and Experimental Studies. Heart 1942, 4, 17-34. [CrossRef] [PubMed]

9. Duque-González, L.; Orrego-Garay, M.J.; Lopera-Mejía, L.; Duque-Ramírez, M. Atrial Infarction: A Literature Review. Cardiovasc. Metab. Sci. 2020, 31, 17-24. [CrossRef]

10. Liu, C.K.; Greenspan, G.; Piccirillo, R.T. Atrial Infarction of the Heart. Circulation 1961, 23, 331-338. [CrossRef] [PubMed]

11. Burnett, J.C.; Kao, P.C.; Hu, D.C.; Heser, D.W.; Heublein, D.; Granger, J.P.; Opgenorth, T.J.; Reeder, G.S. Atrial Natriuretic Peptide Elevation in Congestive Heart Failure in the Human. Science 1986, 231, 1145-1147. [CrossRef] [PubMed] 
12. Yasuda, S.; Nonogi, H.; Miyazaki, S.; Goto, Y.; Haze, K. Hyposecretion of Trial Natriuretic Peptide Due to Associated Right Atrial Infarction in a Patient with Acute Right Ventricular Infarction? Eur. Heart J. 1994, 15, 718-719. [CrossRef] [PubMed]

13. Wencker, M.; Lechleitner, P.; Dienstl, F.; Hauptlorenz, S.; Puschendorf, B. Early Decrease in Atrial Natriuretic Peptide in Acute Myocardial Infarction. Lancet 1987, 329, 1369. [CrossRef]

14. Maeda, K.; Tsutamoto, T.; Wada, A.; Mabuchi, N.; Hayashi, M.; Hisanaga, T.; Kamijo, T.; Kinoshita, M. Insufficient Secretion of Atrial Natriuretic Peptide at Acute Phase of Myocardial Infarction. J. Appl. Physiol. 2000, 89, 458-464. [CrossRef] [PubMed]

15. Lu, M.L.R.; Nwakile, C.; Bhalla, V.; De Venecia, T.; Shah, M.; Figueredo, V.M. Prognostic Significance of Abnormal P Wave Morphology and PR-Segment Displacement after ST-Elevation Myocardial Infarction. Int. J. Cardiol. 2015, 197, 216-221. [CrossRef] [PubMed]

16. Yıldız, S.S.; Keskin, K.; Avsar, M.; Cetinkal, G.; Sigirci, S.; Aksan, G.; Cetin, S.; Okuyan, E.; Kilickesmez, K.O. Electrocardiographic Diagnosis of Atrial Infarction in Patients with Acute Inferior ST-segment Elevation Myocardial Infarction. Clin. Cardiol. 2018, 41, 972-977. [CrossRef] [PubMed]

17. Laukkanen, J.A.; Kurl, S.; Ala-Kopsala, M.; Vuolteenaho, O.; Ruskoaho, H.; Nyyssönen, K.; Salonen, J.T. Plasma N-Terminal Fragments of Natriuretic Propeptides Predict the Risk of Cardiovascular Events and Mortality in Middle-Aged Men. Eur. Heart J. 2006, 27, 1230-1237. [CrossRef] [PubMed]

18. Omland, T.; Bonarjee, V.V.; Nilsen, D.W.; Sundsfjord, J.A.; Lie, R.T.; Thibault, G.; Dickstein, K. Prognostic Significance of NTerminal pro-Atrial Natriuretic Factor (1-98) in Acute Myocardial Infarction: Comparison with Atrial Natriuretic Factor (99-126) and Clinical Evaluation. Heart 1993, 70, 409-414. [CrossRef] [PubMed]

19. Hall, C.; Cannon, C.P.; Forman, S.; Braunwald, E. Prognostic Value of N-Terminal Proatrial Natriuretic Factor Plasma Levels Measured within the First 12 Hours after Myocardial Infarction. J. Am. Coll. Cardiol. 1995, 26, 1452-1456. [CrossRef]

20. Otterstad, J.E.; St. John Sutton, M.G.; Froeland, G.S.; Holme, I.; Skjærpe, T.; Hall, C. Prognostic Value of Two-Dimensional Echocardiography and N-Terminal Proatrial Natriuretic Peptide Following an Acute Myocardial Infarction. Assessment of Baseline Values (2-7 Days) and Changes at 3 Months in Patients with a Preserved Systolic Function. Eur. Heart J. 2002, 23, 1011-1020. [CrossRef] [PubMed] 